\title{
A PRÁTICA LEXICOGRÁFICA NA FORMAÇÃO DO PROFESSOR INDÍGENA
}

\author{
Cosme Batista dos Santos \\ Maria Nazaré Mota de Lima
}

\begin{abstract}
RESUMO: Os estudos do letramento do professor, na perspectiva em que está situada a linha de pesquisa Letramento, identidades e formação de professores do Programa de Mestrado em Critica Cultural da UNEB-Campus II, têm como um dos seus interesses a inserção de professores de diferentes etnias nas práticas de leitura e de produção escrita de relevância cultural. Neste artigo, trazemos um recorte de uma das pesquisas que vem sendo realizada no Programa, sobre a prática de produção lexicográfica de professores indígenas do sertão da Bahia. O objetivo do trabalho é estudar os verbetes produzidos pelos professores, analisando-os em conflito com os verbetes sugeridos nos dicionários tradicionais de língua Portuguesa. $\mathrm{O}$ pressuposto metodológico se filia à pesquisa qualitativa, do tipo pesquisa-ação-formação. $\mathrm{O}$ pressuposto teórico é da Linguística Aplicada, de base interdisciplinar, e envolve um quadro conceitual configurado pelos estudos do letramento intercultural e pelos estudos etnolexicográficos. A produção dos professores levou em conta a língua em uso, como uma demanda de estudos da sociolinguística e, ao mesmo tempo, o registro escrito dos verbetes, como uma demanda da política linguística e da formação do professor no contexto da educação escolar indígena.
\end{abstract}

PALAVRAS-CHAVE: Letramento. Etnolexicografia. Formação do Professor. Escolas Indígenas.

ABSTRACT: The studies of literacy teacher, the perspective that is situated in the line of research literacy, teacher training and identities of the Masters Program in Cultural Criticism of UNEB Campus-II, have as one of their interests inserting teachers different ethnic groups in reading practices and production of written cultural relevance. In this article, we present an excerpt from one of the research that has been conducted in the program, about the practice of lexicographical production of indigenous teachers of the interior of Bahia. The objective is to study the entries produced by teachers, analyzing them in conflict with the suggested entries in dictionaries traditional Portuguese. The methodological assumption joins the qualitative research, the research-action-training, and is the theoretical assumption Applied Linguistics, basic interdisciplinary and involves a conceptual framework set by the studies of literacy and intercultural studies by lexicographical and ethnic backgrounds. The production of the teachers took into account the language in use, such as a demand for studies of sociolinguistics and at the same time, the written record of the entries, such as a demand lexicographic cultural and teacher training in the context of indigenous education.

KEYWORDS: Literacy. Lexicography. Teacher Training. Indigenous Schools.

\section{INTRODUÇÃO}

O estudo sobre o letramento do professor na perspectiva situada deve se ocupar com o fortalecimento ou empoderamento desses profissionais para dar conta das 
demandas de ensino-aprendizagem nas suas comunidades. Muito além de darmos respostas aos professores indígenas para o enfrentamento das dificuldades de ensino nas aldeias, as pesquisas devem se voltar para o estudo colaborativo, em que os problemas dos professores são também os conflitos do pesquisador e, com a mesma preocupação, os produtos da pesquisa tendem a ser também de propriedade dos pesquisados, dos professores, especialmente, quando se trata da formação e do letramento em contextos multiculturais e multilíngues.

Tradicionalmente, os estudos do letramento se dedicaram aos impactos do conhecimento científico e da escrita que o divulgavam na formação do professor e, com isso, os conflitos produtivos da relação teoria e prática e da relação oralidade e cultura escrita, assim como as demandas interculturais e multilíngues foram negligenciadas, enquanto objetos de investigação em letramento do professor. Apesar de tantas demandas culturalmente situadas e relevantes, ainda não temos estudos, nem respostas para os problemas do ensino do léxico na educação básica nas comunidades indígenas e, em especial, em contextos de educação intercultural. Em função dessa lacuna, não é raro encontrarmos, principalmente em livros didáticos e em discursos midiáticos, verbetes estereotipados sobre a cultura local. Normalmente, esses suportes de ensinoaprendizagem tendem a reproduzir imagens distorcidas da cultura indígena e da sua realidade sociolinguística.

Em função dessa ausência, este trabalho, de natureza interdisciplinar, está investigando a variação lexical em uso nas comunidades indígenas e a produção de verbetes culturalmente relevantes para as diferentes etnias envolvidas na Licenciatura Intercultural para Educação Escolar Indígena - LICEEI/UNEB, tendo o professor indígena como autor da referida produção. Mais explicitamente, a pesquisa que estamos desenvolvendo visa à produção de verbetes, tendo como base o universo lexical dessas realidades culturais, trazendo a voz dos povos indígenas e, com isso, consolidar práticas de letramento de professores pautadas na sensibilidade sociolinguística e no domínio do gênero verbete como forma de potencializar as práticas de registro das línguas indígenas na comunidade e nas escolas das aldeias.

A base dos estudos etnolexigráficos neste trabalho é Francisco Javier Perez, cujo enfoque mais abrangente são as reflexões etnográficas em análises de verbetes de dicionários tradicionais das línguas (PEREZ, 2000). Neste artigo, no entanto, o foco 
mais relevante é a formação do professor e, por isso, além das reflexões sobre os significados dos termos da cultura indígena em dicionários de Língua Portuguesa, o artigo focalizará o letramento intercultural (SANTOS, 2008) dos professores, ou seja, a inserção dos educadores na prática lexicográfica configurada pela edição de verbetes da língua em uso em suas aldeias.

Do ponto de vista metodológico, trata-se de uma pesquisa qualitativa do tipo pesquisa-ação-formação, uma vez que a meta é fortalecer os professores indígenas para que, em suas comunidades, possam conhecer as políticas linguísticas oficiais, elaborar problemas de estudos em sociolinguística nas escolas e, dentre outros, produzir verbetes a partir de padrões que possam assegurar os registros escritos das línguas em uso nas escolas e nas aldeias. A produção do corpus está sendo orientada na perspectiva da linguística aplicada, ou seja, tende a valorizar a língua em uso, e a produção de significados está sendo orientada, conforme já apontamos, pela etnolexicografia, uma vez que os verbetes a serem elaborados como produtos deste estudo estão sendo extraídos do acervo lexical das comunidades indígenas, a partir das orientações e significações culturalmente relevantes.

\section{PRESSUPOSTOS TEÓRICOS}

O termo letramento local é a tradução do termo da língua inglesa local literacy, formulado por David Barton. Aqui, leva em conta a natureza da leitura e da escrita embutida nas práticas sociais e, ao contrário das posições que historicamente insistiram na autonomia contextual da escrita, considera que os significados da escrita são relativamente situados, ou seja, depende dos gêneros textuais em uso (MARCUSCHI, 2001), mas também da relação que as pessoas estabelecem com os eventos específicos de leitura e produção escrita em suas comunidades e o modo como se fortalecem a partir da sua inserção em tais eventos (KLEIMAN, 1995; STREET, 2004). Nessa perspectiva, o letramento não se restringe aos efeitos da escrita na mudança cognitiva e cultural, mas também às mudanças que os grupos minoritarizados fazem na e com a escrita, quando a usam em eventos sociais e culturalmente relevantes para solucionar problemas do 
cotidiano, incluindo os problemas da política linguística da comunidade e do ensinoaprendizagem na escola.

Os estudos sobre o léxico, numa vertente culturalmente situada, valoriza a relação entre as diferentes lexias e os povos que as usam. A rigor não é apenas o conhecimento da estrutura linguística da unidade lexical que interessa, mas fundamentalmente, o que as pessoas manifestam e como se manifestam através dela. Qual é a identidade cultural que o léxico revela e qual é identidade lexical que nos faz conhecer certo grupo ou região de usuários da língua? O léxico não pode ser reduzido a uma lista de palavras. As palavras revelam a identidade sociolinguística e cultural do grupo social que as usa e as condições sociais e históricas em que são usadas (ISQUERDO, 1998; MARCUSCHI, 2004). Alguns estudos, seguindo essa vertente, têm se dedicado à etnolexicografia (PEREZ, 2000), por exemplo, investigando os significados das lexias das línguas indígenas nos dicionários de língua portuguesa e investigando a influência cultural e geográfica na definição da identidade lexical da região e/ou local.

Aparecida Neri Isquerdo realizou um estudo sobre o "vocabulário regional na Amazônia acreana”. Trata-se de um estudo sobre o vocabulário do seringueiro do Estado do Acre que objetivou inventariar, descrever e analisar aspectos do léxico utilizado pelo grupo com vistas a verificar em que medida esse nível da língua pode retratar a realidade física, social e cultural da região acreana e do grupo de seringueiros em particular. Em seu estudo, a pesquisadora aponta como uma das suas conclusões:

O predomínio de lexias não dicionarizadas e de emprego específico do grupo recai no campo referente à atividade da seringa (...). Por integrarem o vocabulário básico do grupo com significação já cristalizada no âmbito dos seringais, essas lexias são próprias e específicas de um subsistema regional. Por nomearem referentes muito particulares de um tipo de atividade extrativista, quando ocorre, é resultado de um processo muito lento. Dessa forma, essa parcela significativa de unidades lexicais enriquece sobremaneira o universo lexical da língua portuguesa do Brasil com regionalismos característicos de uma região notadamente marcada pelas suas peculiaridades físico-culturais, econômicas e linguísticas (ISQUERDO, 1998 p. 103).

Outro aspecto importante, também decorrente desse estudo, está ligado aos modos de investigação sobre a identidade lexical regional, por exemplo, destacando o fato de que o isolamento em termos geográficos e sociais e, inclusive, as dificuldades de 
acesso aos meios de comunicação de massa, motivam certa estabilidade lexical na língua falada que, por sua vez, é partilhada e passada de geração para geração sem significativas alterações.

Em nosso corpus, por exemplo, as unidades lexicais são geradas a partir da língua falada em uso em comunidades rurais, indígenas e quilombolas do semiárido baiano e, por isso, as conclusões relativas à lexicologia da Amazônia acreana constituem um antecedente valioso nesta pesquisa. No entanto, a perspectiva de letramento, associada ao fazer lexicográfico, desloca o papel do pesquisador da posição de mapeador e analista da realidade lexicográfica de determinada região, para a posição do etnógrafo, ou que apoia os educadores culturalmente situados na tarefa de produtores de sentido pela escrita a fim de, através dos instrumentos da lexicografia, produzir verbetes e dar visibilidade ao universo lexical da língua em uso, inclusive nos contextos escolares de educação bilíngue.

Elizângela Cardoso, uma professora inventora e em formação no curso de Letras da Universidade do Estado da Bahia - UNEB/Campus III, realizou com seus alunos um estudo piloto da lexicografia sertaneja (CARDOSO, 2012). Em seu trabalho, ela analisou um corpus contendo itens lexicais culturalmente relevantes da região de Canudos, mais especificamente, no município de Uauá (BA). Com a colaboração dos alunos de Língua Portuguesa do ensino médio, Cardoso fez um levantamento de aproximadamente 500 palavras em uso nas comunidades urbanas e rurais do município. Essas palavras foram transformadas em verbetes, como foi o caso da palavra Bacuri, abaixo.

BACURI - s.m. 1. Porco pequeno, 2. Menino. Ex: 1. Leve a lavagem para o bacuri. 2. Esse bacuri já fala que nem homem feito.

O estudo se baseou em uma visão sociocultural do léxico e sugere que a estruturação do gênero verbete deve considerar os seguintes campos constituintes: entrada, categoria gramatical, fonte, área, definição e, por fim, o contexto (DIONISIO, 2007).

No processo, a equipe liderada por Cardoso envolveu estudantes e professores de língua portuguesa para, entre outras atividades, entrevistar moradores antigos das comunidades sertanejas, transcrever os itens lexicais mais estáveis nas narrativas 
populares e, por fim, editar um dicionário regional. Um conflito marcante na edição dos verbetes foi o estudo da lexia umbuzeiro. Uma parte deste estudo mostra que a palavra "umbuzada" não é dicionarizada, inclusive nos dicionários em uso nas escolas. Além disso, o estudo mostra que muitos termos culturalmente estabilizados nos falares sertanejos tendem a ser superficialmente descritos nos dicionários ditos escolares, havendo, por isso, a urgência de estudos lexicográficos, tendo em vista a formação dos professores, assim como a revisão e a produção de novos materiais de ensino das línguas na educação básica.

A introdução dos estudos lexicográficos no processo de ensino-aprendizagem é, portanto, uma experiência de letramento intercultural valorizada nesta pesquisa. No nosso entendimento, a escolarização da prática lexicográfica como parte da pesquisa trará importantes implicações no letramento dos professores e dos alunos indígenas, pois permite uma formação em sociolinguística e em lexicografia para ambos, fortalece a identidade indígena, desmobiliza preconceitos linguísticos em relação aos povos indígenas, suas línguas e suas culturas. Além disso, terá como um dos seus produtos a edição de verbetes ilustrados a serem utilizados pelos alunos e professores nas escolas públicas indígenas e não indígenas. A rigor, a produção do verbete, como gênero de ensino-aprendizagem, centraliza o conhecimento da língua em suas dimensões sintáticosemânticas e pragmáticas, mas favorece o conhecimento da cultura do povo indígena em questão e, ainda, o seu conhecimento semiótico, através da edição de imagens para ilustração dos textos de verbetes.

Trata-se, a rigor, de uma intervenção a partir de demandas que são efetivamente próprias dos professores e dos alunos indígenas, uma vez que os dicionários da língua portuguesa não dão conta da complexidade linguística dos povos nas aldeias e, além disso, não representam em termos de significados a realidade vivenciada pelos membros da comunidade, havendo a necessidade de reinventar a escrita dos verbetes e dos dicionários como parte da formação e do letramento do professor nas escolas indígenas.

A pesquisa, portanto, a partir dos aportes teóricos que mobiliza, busca atingir uma preocupação central da Linguística Aplicada contemporânea, qual seja articular diferentes áreas do conhecimento de modo a visibilizar e valorizar as identidades culturais e as línguas em uso de grupos minoritarizados, contribuindo, dessa maneira, 
nos processos culturais, educacionais e emancipatórios que esses grupos desenvolvem em seus contextos.

\section{ORIENTAÇÃO METODOLÓGICA}

A pesquisa aqui realizada é qualitativa na perspectiva fortalecedora, ou seja, um tipo de pesquisa que se realiza com os sujeitos, partir das demandas de formação e de ação das suas realidades. A partir dessa orientação, é fundamental a associação entre o estudo linguístico do léxico da língua e o estudo do contexto social, econômico e cultural de que o léxico faz parte. Por exemplo, o estudo da unidade lexical "umbuzada", sendo estudada fora do contexto cultural, histórico, geográfico ou ambiental não vai ser outra coisa além de um substantivo feminino. No entanto, quando a sua realidade extralinguística é potencializada, a unidade lexical referida precisa necessariamente traduzir em seus significados o contexto em que faz sentido e para quem e quando faz sentido. Por isso, a definição do verbete que interessa a esta pesquisa inclui, necessariamente, o contexto inter e transcultural, como um campo de informações constituinte de sua estrutura.

Atividades que estão sendo realizadas para constituição, análise e edição de verbetes, por professores indígenas:

a) Seleção de unidades lexicais, tomando como referência as palavras utilizadas pelos alunos nas escolas indígenas e pela comunidade.

b) Formação de organização de campos e de subcampos lexicais. Nesse caso, será considerado, por exemplo: a cultura, a biologia, os fazeres, as artes, etc.

c) Análise dos itens lexicais agrupados nos diferentes campos, apresentando-se a significação de cada um, no contexto territorial do povo indígena em questão.

d) Pesquisa sobre os significados das unidades lexicais, a partir das seguintes atividades: (i) verificação dos significados apresentados pelos dicionários de língua portuguesa; (ii) verificação dos significados apresentados pelos usuários em cada comunidade de falantes;

(iii) comparação, agrupamento e edição dos significados. 
e) Edição de verbetes ilustrados, a partir de agrupamentos de itens lexicais de maior relevância cultural em cada aldeia e em cada realidade de educação escolar indígena.

Para a elaboração deste artigo, embora toda essa orientação tenha sido útil no desenvolvimento das oficinas lexicográficas com os professores indígenas do norte, do sul e oeste da Bahia, o foco é a análise de verbetes produzidos por esses professores e a relação de significados que eles estabelecem com os verbetes editados em dicionários tradicionais da Língua Portuguesa.

A metodologia, portanto, faz emergir e privilegia os conhecimentos linguísticos e as práticas culturais e linguísticas dos professores indígenas, dos seus alunos e dos povos indígenas enquanto constituinte da educação escolar que promovem junto às sociedades indígenas a que pertencem. Propicia, ainda, a reflexão sobre esses aspectos e outros mediados pela linguagem na escola, constituindo-se em evento de letramento do professor, em sua formação intercultural, visando colaborar com eles na sua luta por uma educação diferenciada, específica, comunitária.

\section{RESULTADOS ALCANÇADOS}

A pesquisa em andamento, além de tornar viva a realidade sociolinguística das comunidades indígenas, como uma parte de sua riqueza cultural, também está levando em conta os processos formativos, já que a produção de verbetes está sendo acompanhada pelos professores indígenas participantes da pesquisa e tende a ser, além do registro escrito da memória lexical, uma demanda de letramento de educadores, estudantes e comunidade, de forma que esses sujeitos também se tornem guardadores da sua língua e do seu acervo lexical.

A seguir, veremos os itens lexicais "Caçuá" e "Cangalha", em uso na comunidade indígena Kiriri, que foram editados por Antônio Houaiss, no Pequeno Dicionário Enciclopédico Kogan Larousse e por um grupo de professores da etnia Kiriri, em uma oficina de lexicografia, realizada como parte de sua formação na LICEEI/UNEB. 


\section{Antônio Houaiss}

CAÇUÁ. S.m. Bras. Cesto grande de cipó, vime, etc. para cangalhas.

CANGALHA. S.f. bras. Triângulo de madeira que se enfia no pescoço dos porcos para que não entrem em hortas./- S.m.pl. armação que se coloca no dorso das bestas para sustentar a carga dos dois lados. / fam. Óculos de encaixar sobre o nariz.

\section{Professoras Indígenas Kiriri}

CAÇUÁ. S.m. Objeto feito de cipó da caipora ou de caititu, utilizado pelos indígenas para carregar mantimentos e produtos.

CANGAIA. S.F. Palavra em uso na língua indígena. Objeto feito sobre dois pedaços de madeira em forma de $V$ ao contrário, madeira em forma de tábuas, couro, tecido e crôa; é utilizado em cima do animal para carregar pessoas, barricas, cambites e caçuás.

No contexto da pesquisa-ação-formação, os resultados estão sendo encontrados a partir de um estudo das relações intertextuais entre os verbetes. Em outros termos, está sendo interessante verificar as diferenças e a relevância do discurso informacional presente em cada verbete. Por exemplo, no verbete "Caçuá", a extensão da imagem do "cesto grande de cipó", no verbete do dicionário, para "objeto de cipó de caipora e caititu", no verbete das professoras indígenas. No verbete das professoras, a descrição de "cesto", aparentemente imprescindível, não aparece, por outro lado, aparece uma descrição mais densa do objeto "cipó", isto é, "cipó de caipora e caititu" que, no nosso entendimento, são informações imprescindíveis para a realidade cultural. Além disso, vale destacar o grau de explicitude conquistada no verbete "Cangalha". No verbete do dicionário de língua portuguesa, "Cangalha" é, analogicamente, uma "armação", enquanto que no verbete das professoras, "cangalha" é um "objeto de madeira em forma de V ao contrário".

Através da inserção dos professores na experiência de produção dos verbetes e nas leituras de lexicografia, nós percebemos que o trabalho realizado corresponde e atende a uma expectativa de que ele também pode ser responsável pelo seu letramento e por uma parte importante da sua formação linguística. As escolas recebem materiais didáticos, incluindo dicionários e livros que fornecem significados quase sempre 
equivocados dos elementos da cultura indígena e da realidade vivenciada pelos povos indígenas em suas comunidades. Um dos conflitos muito produtivo pode ser verificado em relação à ausência de palavras tão importantes para a cultura, como "umbuzada", um alimento muito comum na culinária do sertão brasileiro, em geral.

Da mesma forma, podemos tirar muito proveito dos conflitos que são estabelecidos a partir das definições estereotipadas em dicionários de Língua Portuguesa. Um exemplo desse conflito se manifestou com a apresentação da definição dicionarizada da palavra "Rancho" como um tipo de habitação "pequena e pobre". Esse significado gerou inquietações na comunidade de professores indígenas, já que no entendimento de muitos índios a designação "pobre" é preconceituosa, não representa o significado cultural do objeto "rancho" e, numa situação de educação escolar indígena, pode gerar constrangimentos nas crianças.

A rigor, são situações em que os professores se sentem muito encorajados para assumir o conflito e que, por isso, são também situações fundamentais para o início de um processo de letramento em que os educadores indígenas, assim como os demais alfabetizadores do semiárido, sejam os autores das questões, das pesquisas e da formulação de outros entendimentos sobre as suas línguas, especificamente sobre o léxico. O nosso papel é encorajá-los a fazer uma lexicografia culturalmente relevante e coerente com a realidade multicultural brasileira e com seus processos societários, especialmente.

O papel do pesquisador do letramento do professor, nas perspectivas dos novos letramentos (STREET, 2010) não pode se furtar a isso, ou seja, fortalecer os educadores para a realização de tarefas que precisam ser feitas, tendo em vista o preenchimento das lacunas, desse espaço em branco que se instituiu nas políticas de formação do professor e nas políticas de educação linguística dos alunos indígenas e não indígenas, focalizando sua afirmação identitária e das comunidades tradicionais, especificamente das comunidades e escolas indígenas.

Brian Street, discorrendo sobre as contribuições da etnografia nos estudos de letramento, aponta a seguinte conclusão:

A relação do professor com seus alunos tem de ser diferente, quando se sabe que o aluno não é um espaço vazio a ser preenchido. Os alunos estão engajados em uma sociedade, em uma cultura em que a escrita pode ocupar grande espaço. Cada um deles pode não ter conhecimento de todas essas escritas, eles podem não se sentir 
competentes o bastante para fazer o trabalho que querem e precisam fazer. Portanto, estamos lá para ajudar a fazer: deixem-nos ajudar naquilo em que vocês querem ajuda. (STREET, 2010 p. 49).

O papel do agente de letramento, seja formador ou pesquisador, passa a ser muito importante na formação do professor indígena ou mesmo em contextos outros, mais ainda quando a meta for apoiar os educadores e alunos nas tarefas de inserção letrada, em especial, para as práticas de leitura e de produção escrita que sejam definitivamente relevantes para a cultura.

\section{CONCLUSÃO}

No início deste artigo, foi dito que o objetivo do trabalho é estudar o letramento dos professores indígenas, a partir da análise de verbetes produzidos por esses professores em conflito com os verbetes de dicionários tradicionais da língua portuguesa. Como já sinalizamos, portanto, os itens lexicais em uso nas comunidades, assim como os seus verbetes são apenas o ponto de partida de uma formação mais ampla e mais completa do professor e do aluno. Evidentemente que, após a análise dos resultados, o trabalho de edição dos verbetes, realizado por professores indígenas, aponta para a necessidade de uma inserção crescente desses sujeitos na prática de registros de sua língua e na prática de formação da sensibilidade sociolinguística dos alunos e da comunidade indígena como um todo. Numa perspectiva mais ampla, ainda, podemos propor que em cada escola indígena sejam construídos pequenos laboratórios de lexicografia para que, no futuro, possamos tornar mais visível e mais atraente a importância desse trabalho no currículo escolar e na vida dos professores e alunos em contextos multiculturais e multilíngues.

Do ponto vista prático, a criação desses laboratórios deverá potencializar as atividades constantes de edição de verbetes em diferentes áreas do conhecimento e em diferentes momentos da vida escolar. Os arquivos produzidos pelas escolas deverão considerar, inicialmente, a riqueza lexical das comunidades e, nesse sentido, é fundamental que os educadores ensinem os alunos a perderem o preconceito ao falar/escutar sua língua. Em seguida, torna-se importante o levantamento dos 
significados apresentados pelos dicionários de língua portuguesa e, finalmente, o estabelecimento dos conflitos entre as representações dos dicionários e as dos grupos culturalmente situados. A partir desse estudo, a escola deve utilizar esses instrumentos de formação para apoiar os alunos na edição de verbetes da sua própria língua, certamente, na concretização de uma política linguística pautada na demanda específica dos usuários, no caso demanda de cada povo indígena.

\section{REFERÊNCIAS}

CARDOSO, Elisângela. A sociolinguística sertaneja: uma experiência lexicográfica em escola pública de Uauá-Ba. $1^{\mathrm{a}}$ ed. Juazeiro: UNEB-DCH, 2012. 81p.

DIONÍSIO, Ângela Paiva. Gêneros textuais e ensino. $5^{\mathrm{a}}$ Ed. Rio de Janeiro: Editora Lucerna, 2007. 229 p.

HOUAISS, Antônio. Pequeno dicionário enciclopédico Kogan Larousse. $6^{\mathrm{a}}$ ed. São Paulo: Editora Larousse do Brasil, 1987. 1634 p.

ISQUERDO, Aparecida N. Vocabulário regional da Amazônia acreana. ALFA: revista de linguística. p. 93-107. 1998. Acesso em julho de 2012.

KLEIMAN, Angela. B. Modelos de letramento e as práticas de alfabetização na escola. In. KLEIMAN, A. (org.) Os significados do letramento: uma nova perspectiva sobre a prática social da escrita. $1^{\text {a }}$ ed. Campinas, SP: Mercado de Letras, 1995.p.291.

MARCUSCHI, Luiz A. O léxico: lista, rede ou cognição social? In: Lígia Negri, Maria José Foltran e Roberta Oliveira (Orgs.). $1^{\text {a }}$ ed. Sentido e Significação: em torno da obra de Rodolfo Ilari. São Paulo: Contexto, 2004. p.263-284

PEREZ, Francisco Javier. Dicionários, discursos etnográficos e universos léxicos: propuestas teoricas para la compreension cultural de los dicionários. $1^{\mathrm{a}}$ ed. Caracas: Fundacion Centros de Estudios Latinoamericanos Romulo Gallego: Universidad Católica Andrés Bello, 2000. 148p.

SANTOS, Cosme B. Letramento e comunicação intercultural: o ensino e a formação do professor. In. Edleise Mendes e Lúcia Castro (orgs). Saberes em Português. $1^{\mathrm{a}}$ ed. Campinas: Pontes, 2008, p.79-94

STREET, Bryan. Os novos estudos sobre o letramento: histórias e perspectivas. In: Marildes Marinho e Gilcinei Teodoro Carvalho (Orgs). Cultura Escrita e Letramento. $1^{\mathrm{a}}$ ed. Belo Horizonte: Editora da UFMG, 2010. p. 54-67.

RECEBIDO EM: 01 de novembro de 2012

APROVADO EM: 10 de dezembro de 2012 